Microscopy

\section{Coming Events}

Due to COVID-19, please check to see if the listed events have been postponed or cancelled.

2021

ICMCMM 2021: 15th International

Conference on Macromolecular Chemistry and Molecule Microscopy

June 24-25, 2021

Oslo, Norway

https://waset.org/macromolecular-chemistry-and-

molecule-microscopy-conference-in-june-2021-in-oslo

5th International Congress on 3D

Materials Science (3DMS 2021)

June 29-July 2, 2021

Washington, DC

www.tms.org/3DMS2021

mmc2021: Microscience Microscopy Congress 2021

July 5-8, 2021

Virtual

www.mmc-series.org.uk

Microscopy \& Microanalysis 2021

August 1-5, 2021

Virtual

www.microscopy.org/events/future.cfm

MC 2021 Joint Meeting of Dreiländertagung \& Multinational

Congress on Microscopy

August 22-26, 2021

Virtual

www.microscopy-conference.de

2021 Gordon Research Conference on Three-Dimensional Electron

Microscopy

October 31-November 5, 2021

Newry, ME

www.grc.org/three-dimensional-electron-

microscopy-conference/202

2022

Microscopy \& Microanalysis 2022

July 31-August 4, 2022

Portland, OR

www.microscopy.org/events/future.cfm

\section{3}

Microscopy \& Microanalysis 2023

July 24-28, 2023

Minneapolis, MN

www.microscopy.org/events/future.cfm

\section{4}

Microscopy \& Microanalysis 2024

July 28-August 1, 2024

Cleveland, $\mathrm{OH}$

www.microscopy.org/events/future.cfm

\title{
Do Bird Migration and Childhood Leukemia Have Something in Common?
}

\author{
Stephen W. Carmichael \\ Mayo Clinic, Rochester, MN 55905 \\ carmichael.stephen@mayo.edu
}

It is possible that both the migration of birds (and other animals) and childhood leukemia involve cells that are sensitive to magnetic fields. In an elegant study [1] that required the development of a unique microscope, Noboru Ikeya and Jonathan Woodward may have identified the mechanism by which cells respond to a magnetic field; this in turn could be related to both animal migration and human health. The study of magnetic field effects on biological processes is extremely challenging since the effects are typically weak and highly variable. What was needed to convincingly demonstrate cellular magnetic field responses was a measurement in which the direct influence of the magnetic field on living cells or subcellular structures was clearly observed in real time. Ikeya and Woodward have provided this.

A strong candidate for a mechanism by which cells sense magnetism is the so-called radical pair mechanism (RPM). It has been well-established that some chemical reactions, that proceed through the formation of shortlived reaction intermediates called radical pairs (RPs), can be influenced by the application of weak magnetic fields. Indeed the key candidate molecules proposed as being responsible for the magnetic "compass" in migratory birds are blue light-photosensitive proteins called cryptochromes, which contain flavin adenine dinucleotide (FAD) and that generate RPs when photoexcited. Flavins are also one of the molecules responsible for the autofluorescence of cells. Crucial to the RPM is the ability of RPs to mix between different spin states, the efficiency of which can be altered by the application of a magnetic field. The subsequent "spin-selective reaction" results in different fates for the RPs depending on their spin state and, thus, on the magnetic field. In this study the application of a magnetic field alters the amount of time the flavin molecules spend in a fluorescent state, resulting in a change of the observed fluorescence signal caused by their photoexcitation. Under certain circumstances, the fluorescence will decrease as the magnetic field is applied.

Ikeya and Woodward chose to use HeLa cells because they are the most extensively studied immortal human cell line. The goal was to demonstrate that autofluorescence in these cells showed a magnetic field effect consistent with the RPM and present evidence that the source of this effect could be explained by known reactions to blue light photoexcitation. Using their unique microscope that was capable of applying a magnetic field in the low milli-tesla range directly to a cell, they showed a small but clear change in fluorescence in response to the magnetic field (Figure 1). Specifically, a decrease in autofluorescence of 1 to $2.5 \%$ was observed in real time when the magnetic field was applied. The variation in autofluorescence change meant that the effect of the magnetic field is more clearly visible in some cells than others. These observations led Ikeya and Woodward to suggest that the simplest explanation is probably correct (Occam's razor); specifically, flavin-based RPs are responsible for the observed magnetic responses in the cells. 
Bright field

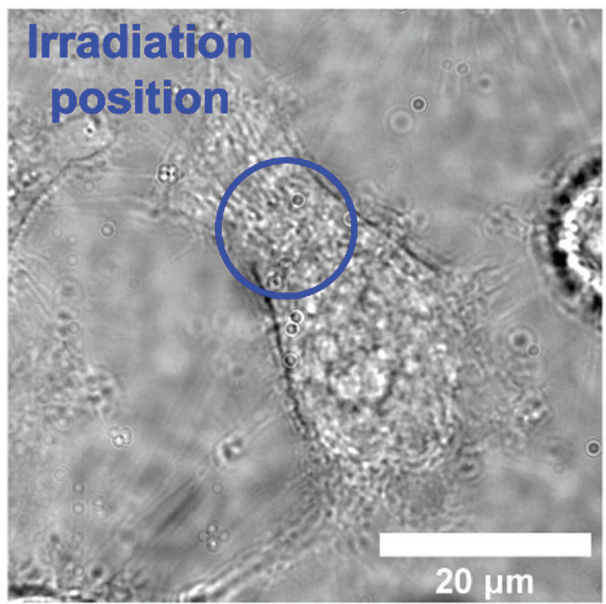

Fluorescence

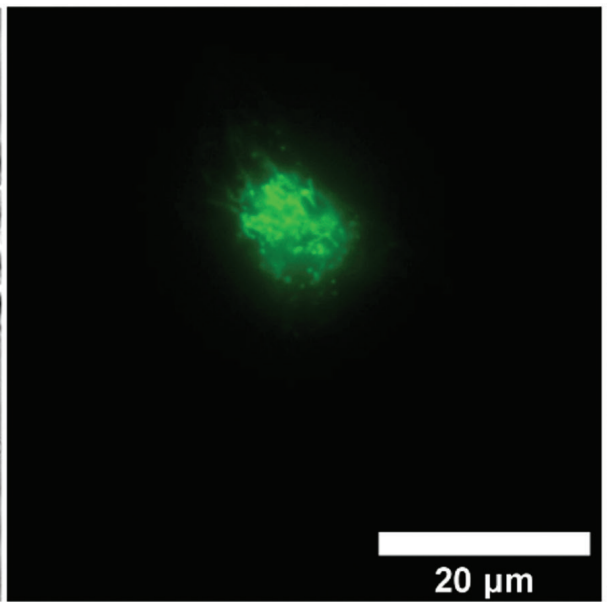

Merge

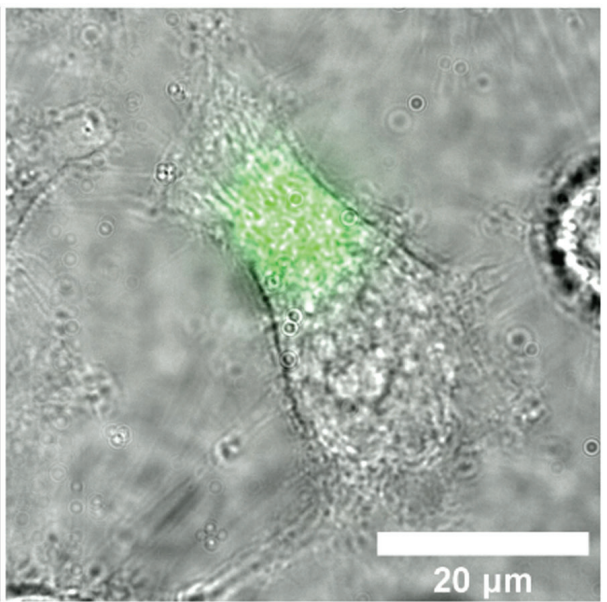

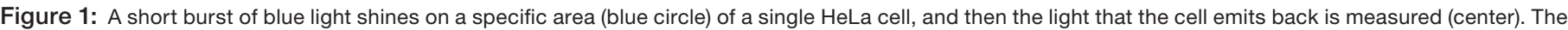
cellular autofluorescence occurs only in the area that was irradiated with blue light (center, right) (C) Ikeya and Woodward.

To confirm this hypothesis, Ikeya and Woodward then went on to provide direct evidence that the autofluorescence signal arises from flavins and not other species of molecules. To do this they modified their microscope to allow the fluorescence spectrum of individual cells to be captured. This is technically challenging due to the very weak signals and rapid photobleaching. A significant finding was that the fluorescence spectra in single $\mathrm{HeLa}$ cells was very similar to that of FAD in a buffer at physiological $\mathrm{pH}$, supporting the hypothesis that this, and/or other flavins, is responsible for the cellular response. Subsequent observations led them to conclude with confidence that flavins play the key role in the observed response to a magnetic field. Additional observations showed that fluorescence is not evenly distributed throughout cells, leading Ikeya and Woodward to conclude that the signal arises directly from mitochondria. They also demonstrated that mitochondria moved normally during the experiments indicating that the cells were alive.

This is the first time that flavins have been observed in real time responding to a magnetic field in living cells. The application of this new knowledge to the well-studied, but still unexplained, phenomenon of animal migration will be exciting. Ikeya and Woodward are also interested in whether or not their results may have any significance to the reported effects of very weak environmental electromagnetic fields on causes of disease in humans, specifically childhood leukemia.

\section{References}

[1] N Ikeya and JR Woodward, Proc Nat Acad Sci 118 (2021) e2018043118. https://doi.org/10.1073/pnas.2018043118

[2] The author gratefully acknowledges Dr. Jonathan Woodward for reviewing this article.

\section{Nanopositioning / Automation for Microscopy \& Imaging}

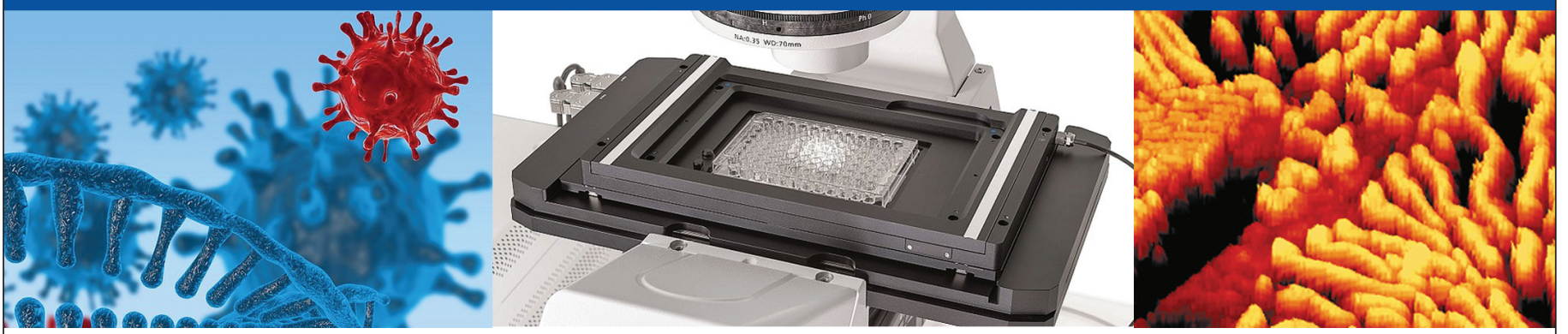

\begin{tabular}{lllll}
\hline $\mathbf{L} 1$ PIEZO & PERFORMANCE & NANO & Ask PI@pi-usa.us | www.pi-usa.us \\
TECHNOLOGY & AUTOMATION & POSITIONING & 50 Years Experience | Global Support \\
\hline
\end{tabular}

